\title{
BMJ Open Best practice when working with suicidal behaviour and self-harm in primary care: a qualitative exploration of young people's perspectives
}

India Bellairs-Walsh (D) , ${ }^{1,2}$ Yael Perry, ${ }^{3}$ Karolina Krysinska, ${ }^{1,2}$ Sadhbh J. Byrne, ${ }^{1,2}$ Alexandra Boland, ${ }^{1,2}$ Maria Michail, ${ }^{4}$ Michelle Lamblin, ${ }^{1,2}$ Kerry L. Gibson, ${ }^{5}$ Ashleigh Lin, ${ }^{3}$ Tina Yutong Li, ${ }^{1,6}$ Sarah Hetrick, ${ }^{1,7}$ Jo Robinson ${ }^{1,2}$

To cite: Bellairs-Walsh I, Perry Y, Krysinska K, et al. Best practice when working with suicidal behaviour and self-harm in primary care: a qualitative exploration of young people's perspectives. BMJ Open 2020;10:e038855. doi:10.1136/ bmjopen-2020-038855

- Prepublication history and additional material for this paper is available online. To view these files, please visit the journal online (http://dx.doi.org/10. 1136/bmjopen-2020-038855).

Received 26 March 2020 Revised 09 September 2020 Accepted 24 September 2020

A Check for updates

(c) Author(s) (or their employer(s)) 2020. Re-use permitted under CC BY-NC. No commercial re-use. See rights and permissions. Published by BMJ.

For numbered affiliations see end of article.

\section{Correspondence to} Ms India Bellairs-Walsh; india.bellairs-walsh@orygen. org.au

\section{ABSTRACT}

Objectives General practitioners (GPS) have a key role in supporting young people who present with suicidal behaviour/self-harm. However, little is known about young people's opinions and experiences related to GPs' practices for such presentations, and their decisions to disclose suicidal behaviour/self-harm to GPs. Additionally, existing guidelines for the management of suicide risk and/or self-harm have not incorporated young people's perspectives. This study aimed to explore young people's views and experiences related to the identification, assessment and care of suicidal behaviour and self-harm in primary care settings with GPS.

Design, setting and participants Two qualitative focus groups were conducted in Perth, Western Australia, with 10 young people in total $\left(M_{\text {age }}=20.67\right.$ years; range: $16-$ 24). Data were collected using a semistructured, openended interview schedule and analysed using thematic analysis.

Results Five major themes were identified from the focus groups. (1) Young people wanted a collaborative dialogue with GPs, which included being asked about suicidal behaviour/self-harm, informed of treatment processes and having autonomy in decision making; (2) young people were concerned with a loss of privacy when disclosing suicidal behaviour/self-harm; (3) young people viewed labels and assessments as problematic and reductionistdisliking the terms 'risk' and 'risk assessment', and assessment approaches that are binary and non-holistic; (4) young people highlighted the importance of GPs' attitudes, with a genuine connection, attentiveness and a non-judgemental demeanour seen as paramount; and (5) young people wanted to be provided with practical support and resources, followed-up, and for GPs to be competent when working with suicidal behaviour/selfharm presentations.

Conclusions Our study identified several concerns and recommendations young people have regarding the identification, assessment and care of suicidal behaviour/ self-harm in primary care settings. Taken together, these findings may inform the development of resources for GPs, and support progress in youth-oriented best practice.

\section{Strengths and limitations of this study}

- This study is novel in its focus; while the barriers for both young people and general practitioners (GPS) are well documented regarding the receipt and provision of care for mental health concerns, little is known about young people's views specific to the care of suicidal behaviour and self-harm.

- Qualitative focus groups were used to explore what young people consider to be best practices for GPs, which can help to inform policy and practice recommendations, as well as resources for the primary care setting.

- To enhance rigour, we used robust data collection and analysis procedures including conducting group data consensus activities and undertaking and reporting the study in line with the Consolidated Criteria for Reporting Qualitative Research.

- Convenience sampling based on interest in participating and geographical region, as well as the relatively small and heterogeneous sample, may limit the robustness and generalisability of the findings.

\section{INTRODUCTION}

Suicide is the leading cause of death among young Australians, and accounted for over one-third of deaths $(38.4 \%)$ in those aged 15-24 years in 2018. ${ }^{1}$ Suicidal behaviour (defined here as suicidal ideation, suicide plans and suicide attempts $)^{23}$ and self-harm (ie, deliberately injuring oneself regardless of suicidal intent) ${ }^{45}$ are much more prevalent than suicide. Approximately 3.4\% of Australian aged 16-24years old have reported serious suicidal ideation in the previous 12 months, ${ }^{6}$ and approximately $6 \%-8 \%$ of those aged 15-24 report having self-harmed. ${ }^{78}$ As suicidal behaviour and self-harm are known risk factors for suicide, as well as premature death via other causes, ${ }^{9-14}$ their early detection is an important step towards suicide prevention in young people. ${ }^{15}$ 
General practitioners (GPs) are often the first point of contact with the healthcare system. ${ }^{16}$ In Australia, GPs frequently act as both gateway providers (by connecting people with services) and gatekeepers (by providing service referrals that allow for reduced treatment costs). ${ }^{17}$ Research shows that between $62 \%$ and $80 \%$ of people under the age of 35 years contact a GP in the year prior to suicide, ${ }^{18} 19$ and $23 \%$ in the month prior. ${ }^{18}$ Additionally, $58 \%$ of young people who engage in self-harm had seen their GP in the previous 6 months. ${ }^{20}$ As such, primary care presents a valuable opportunity for the identification, response to, and management of signs of suicidal behaviour and self-harm in young people. ${ }^{21}$

Training standards for general practice recommend that GPs are able to identify warning signs and risk factors for suicide and respond appropriately. ${ }^{22}$ Recently, however, there has been a shift away from the use of more traditional categorical-based risk assessment methods that classify patients into 'low-risk' or 'high-risk' groups, towards holistic, psychosocial-based assessment models. ${ }^{23}{ }^{24}$ Traditional approaches that rely on scales and classifications to predict future suicide or the repetition of self-harm have been shown to have seriously limited psychometric properties and clinical usefulness, ${ }^{25-27}$ and as such, psychosocial approaches to assessing risk have been recommended instead. ${ }^{528}$ These should encompass 'a direct conversation with a patient about their suicidal thoughts, plans and intent', ${ }^{29}$ incorporate essential information about mental state, current and historical risk and protective factors, main stressors, and current supports available to the patient, and focus on individual needs and client narratives. ${ }^{24}$ However, it is possible that GPs engage in a variety of practices to conceptualise the extent and possibility of suicidal behaviour and/or self-harm, including approaches that are no longer recommended as best practice. Additionally, while there have been some clinical recommendations made for GPs when assessing the risk of suicide in young people in both Australia ${ }^{30}{ }^{31}$ and the UK, ${ }^{32}$ many existing guidelines are not youth specific, nor have they incorporated young people's perspectives on risk assessment processes in general practice. ${ }^{529} 3334$

The omission of young people's perspectives is problematic, as young people report various barriers to helpseeking and the disclosure of mental health concerns in the primary care setting. ${ }^{35}$ These include a lack of awareness that GPs can provide treatment for psychological problems, ${ }^{36-38}$ concerns regarding confidentiality, ${ }^{37} 39$ and embarrassment around discussing psychological problems and self-harm. ${ }^{38}{ }^{40}$ Young people also report that GPs may have a limited appreciation of youth-specific health concerns and unsatisfactory communication and interpersonal skills. ${ }^{37}{ }^{41}$ In addition, suicidality may be disguised as physical complaints, ${ }^{42}$ and suicidal ideation in and of itself may act as a substantial barrier to disclosure and help-seeking in the primary health setting. ${ }^{43}$ A lack of acceptable youth-friendly and youth-oriented service models may further impact help-seeking, ${ }^{44}$ and high turnover can negatively affect the establishment of rapport and ongoing relationships between doctors and their young patients. ${ }^{41}$ GPs themselves have also previously outlined the difficulties they experience in identifying risk due to a lack of disclosure by young people. ${ }^{45}$

While these are important findings, there remains limited focus on young people's experiences regarding the disclosure, identification, assessment and care of suicidal behaviour and self-harm in primary care, including their preferred approaches to the conceptualisation of risk, particularly through a qualitative lens. Thus, the current study aims to address this gap by examining youth perspectives on what constitutes best practice by GPs when working with young people at risk of suicidal behaviour and self-harm. Specifically, the research question was: what are the views and experiences of young people in regards to the identification, assessment and care of suicidal behaviour and self-harm in primary care settings?

The involvement of young people in research about services that support them is in line with participatoryorientated research frameworks ${ }^{46} 47$ and guidelines on consumer participation in health and medical research. ${ }^{48}$ Knowledge of young people's preferences can help improve the experiences of other young people who present to GPs with these presentations, and inform the development of primary care resources.

\section{METHODS}

\section{Study design and setting}

This study employed a qualitative design that utilised face-to-face focus groups to explore the research question. The framework informing data collection and analysis was a mixed inductive-deductive, realist, experiential approach. ${ }^{49}$ Interviews and data analysis were guided both by previous research on young people's experiences of healthcare services, as well as being open to unforeseen responses and patterns, and focused on giving voice to participants through their expressed experiences, meanings and realities. ${ }^{49}$ The study was conducted in Australia by researchers from Orygen in Melbourne and the Telethon Kids Institute in Perth. It was undertaken in the Perth South Primary Health Network region of Western Australia, under the auspices of the National Suicide Prevention Trial. ${ }^{50}$ The study is presented in line with the Consolidated Criteria for Reporting Qualitative Research, ${ }^{51}$ with the checklist presented in online supplemental file 1 .

\section{Patient and public involvement}

The study was conceptualised and designed in collaboration with a youth advisor (TYL), who also assisted in the development of the interview schedule and question testing with young people. During a consultation process at Orygen, young people's views were sought on the design of the study material, in which they provided feedback on the interview questions to ensure that these were accurately capturing rich information on the areas of interest. 


\section{Participants and recruitment}

Ten young people took part in the study: seven identified as female and three as male. Further demographic data were collected from nine participants (missing from one participant). The mean age of participants was 20.67 years $(S D=2.82$; range: 16-24). Six were born in Australia, and English was the primary language spoken at home for all but one. No participants identified as Aboriginal or Torres Strait Islander. Five indicated having had previous experience of undergoing a suicide/self-harm risk assessment with a GP.

Convenience sampling methods were employed, with targeted advertisements posted on the Facebook, Twitter and webpages of youth mental health organisations across Perth, including headspace centres, the Telethon Kids Institute, The Commissioner for Children and Young People, and the Youth Affairs Council of Western Australia. To take part, young people had to be aged between 16 and 25 , and advertisements specified that we sought to recruit those with experience of discussing suicidal behaviour and/or self-harm with a GP (see online supplemental file 2). However, as a risk assessment for suicide/self-harm is a very specific process, having direct experience of undergoing a risk assessment, or having a history or presence of suicidal behaviour/self-harm was not necessary for inclusion in the sample. Rather, we wanted to include young people who may not have undergone a risk assessment $(n=3)$, as well as those where risk might not have been present, yet was still asked about by their GP. This could offer valuable insights into the barriers that may prevent risk identification and assessments from occurring in the presence of risk, as well as preferences for these processes even in the absence of risk-hence providing additional perspectives and depth of understanding. ${ }^{52}$

\section{Materials}

A brief questionnaire was used to collect information on the demographic variables reported for participants above. Focus groups followed a semistructured, openended interview schedule, which was piloted with young people at Orygen. The schedule covered six topics: (1) participants' perceptions on the term 'risk assessment'; (2) barriers and enablers to help-seeking in primary care; (3) important considerations for GPs when communicating with young people about suicidal behaviour and/ or self-harm; (4) experiences of assessment processes for suicidal behaviour and/or self-harm; (5) perspectives on what constitutes best practice for GPs when responding to a young person's disclosure of suicidal behaviour and/ or self-harm; and (6) suggested areas of improvement for GPs when working with young people who have these presentations. The specific interview schedule is outlined in online supplemental file 3. Because depression is a known risk factor for both suicidal behaviour and selfharm, ${ }^{1253}$ this was also included in the interview schedule, and was additionally useful as a soft entry point. Furthermore, although the language throughout the schedule refers more broadly to 'professionals', the focus was narrowed to refer to GPs specifically during the interviews themselves.

\section{Procedures}

Young people who expressed interest in participating were provided with the study information, and recruited into one of two focus groups which took place in June 2018 at two youth services in the Perth South region. Participants selected to take part in the focus group session that was most convenient and accessible to them, in order to provide autonomy and decrease any potential burdens. ${ }^{54}$ At the start of each focus group participants completed the demographic questionnaire, and following this, two authors (SJB, YP or JR) facilitated each group. Each ran for 75 minutes and were audio-recorded and transcribed verbatim for data analysis. Participants were remunerated AU $\$ 30.00$ per hour for their time. In terms of determining sample size, saturation has traditionally been used as a criterion in qualitative research. ${ }^{56}$ However, more recently researchers have argued that the measure should be that the data are sufficiently rich to support the analysis, and are able to generate new understandings ${ }^{57}$ Following the second focus group, we judged the richness and novelty of the data to be sufficient to address these criteria and the aim of the study.

\section{Data analysis}

Transcripts were imported into a qualitative software program to assist with data management and analysis (NVivo V.11, 2015; QSR International). Data were analysed following the processes of thematic analysis described by Braun and Clarke. ${ }^{58}$ At the first step, author IBW familiarised and immersed themselves in the data by reading and rereading the transcripts and field notes and listening to the audio-recordings to identify potential patterns in the data, develop ideas and search for meanings. The second step involved generating initial codes, and coding for as many potential themes and patterns as possible. Next, searching for themes was undertaken, in which codes were collapsed or clustered into their overarching themes, and relationships between codes, themes and subthemes were identified. IBW also constructed thematic maps and undertook memo-writing throughout the analysis process, to assist with theme development and refinement. To enhance validity and rigour, disconfirming case analysis was conducted throughout to consider data that did not fit with the themes and patterns identified. ${ }^{59}$ Notably, young people's views were well-aligned both across and within the focus groups, and we identified only very minor instances of differing perspectives which are reported in the relevant themes below. Transcripts were also second coded by another author who was in the same research team but independent of this particular study $(\mathrm{AB})$. The second coder followed the same process as the first, and the two then met to challenge the codes, categories, and themes identified. IBW then met with another two members of the authorship group (KK and KLG) to discuss the properties of the codes and themes 
and develop a thematic structure to the analysis. Where the authors disagreed, they discussed the data and subsequent codes until consensus was reached. These activities helped to refine the themes and develop them into a more concise and coherent account. It also aimed to improve the fidelity of the analysis by including 'several judges throughout the data analysis process to foster multiple perspectives' and allowing consensus about the 'meaning of the data'. 60

\section{RESULTS}

Five major inter-related themes were identified:

- Wanting a collaborative dialogue.

- Fearing a loss of privacy when disclosing risk.

- Labels and assessments as problematic and reductionist.

- The importance of GPs' attitudes.

- The provision of practical support.

While the focus of the study was on suicidal behaviour and self-harm, participants also spoke more broadly about their experiences of mental health presentations to GPs.

\section{Wanting a collaborative dialogue}

Many participants emphasised the importance of having a collaborative and ongoing dialogue with their GP as part of their care. They described wanting their GP to proactively explore their mental health and suicidal behaviour/self-harm as part of this dialogue. While there was one participant who described having a 'good experience' with a GP who considered their mental health as a potential factor when they presented with physical issues, others spoke of instances where GPs had not fully investigated their suicidality or mental health issues, and instead, had focused on their physical health only:

My iron's always low and they're like, 'That's why you're tired.'... the mental health question's never been asked. (Female, FG 2).

Participants described a range of barriers that prevented young people from raising concerns about mental health issues, suicidal behaviour and self-harm with their GP. These included young people often having a lack of mental health literacy, as well as experiencing the consequences of mental health symptoms themselves, such as feeling hopeless and 'like a burden'. Rather than the onus being on the young person to disclose their difficulties, participants wanted their GPs to initiate the conversation around mental health, suicide and self-harm, stating that this could 'change everything'. They described how failure by GPs to ask could lead to a missed opportunity to get help:

If you go and see a GP, like (you think), 'Well this is a doctor, they know everything. They're a professional, surely they'll ask me everything', and they don't. It's pretty easy to walk out of that appointment and never go back to explore that again... They should definitely be-it just should be something that they at least explore. Especially with young people who might not be wanting to come forward and might not know. (Female, FG 2).

Participants also spoke of feeling ill-informed about the role of GPs and aspects of their care, and wanted their GP to share this information with them as part of a dialogue. They wanted to understand what kind of support GPs could offer them if they felt at risk of suicide:

I had no idea what I was supposed to be getting from (the GP). Like, I know with a psych what I'm supposed to be getting... but, yeah. (Female, FG 2).

Participants spoke about wanting greater transparency with the reasons for, and consequences of, treatment options. They discussed the importance of having a collaborative dialogue with their GP regarding treatment decisions. Giving the young person autonomy to make informed choices was seen by participants as more positive than GPs controlling all aspects of their care:

Adequate conversation about how (the GP is) going to address the situation and input from the young person rather than (the GP) just taking over and being, 'Well this is what you're going to do, and this is what you're going to have.' I feel like it's empowering for the young person to have control. they feel less helpless. If (the GP is) like, 'Well, I would prefer to do this actually' and 'We'll try this first and if that doesn't work we can try this later' and just options, and I guess for (the young person) to maintain their own control over the situation. (Female, FG 2).

Overall, participants emphasised that a collaborative dialogue facilitated by GPs around mental health and suicidal behaviour/self-harm should be standard practice, and that this should include information and autonomy for the young person.

\section{Fearing a loss of privacy when disclosing risk}

Participants described fearing the consequences of disclosing mental health difficulties, suicidal behaviour and self-harm to GPs, due to concerns with the confidentiality and privacy of their medical records. They expressed apprehension about their mental health or suicide risk status being recorded, what may happen to this information, and who may be able to access it in the future:

In terms of the GP, I know for a fact that in the future we will be getting an online thing, where... all the information will be online up in there, and that's something that could worry people in terms of 'My information is going to be on there and people could easily access it.' (Female, FG 1 ).

Participants also highlighted that uncertainty around what personal information was being recorded by GPs, and what would happen to that information, negatively influenced their level of honesty and disclosure: 
When they're typing, you kind of feel (like), 'What are they typing? Now I feel like maybe I shouldn't say that. What if they type it into the system?', things like that. (Female, FG 1).

Conversely, they stated that being kept informed by GPs about the outcomes of sharing their information would enhance feelings of comfort and safety and the likelihood of risk disclosure:

Being informed and making that person comfortable and saying, 'That's confidential, it's just going to be between me and you'... I think that's definitely a positive approach. (Female, FG 1).

\section{Labels and assessments as problematic and reductionist}

Participants viewed the language around 'risk' and 'risk assessment' as problematic. The term 'assessment' elicited feelings of being a 'testing product', while the term 'risk' was seen as 'negative' and 'intimidating':

I think the word 'risk' can sort of make you feel like a hazard. (Female, FG 1).

Instead, they wanted the language to have positive connotations, be 'more inviting', and have 'more warmth to it', and felt that this would encourage help-seeking behaviour. A few participants suggested incorporating the term 'well-being' as an alternative. Many also expressed their concerns towards being labelled 'at-risk', as well as having a mental health label attached to them:

In terms of say suicide or that kind of issue, you don't want it to be kind of labelled there... I think you get scared... to be labelled at that moment. (Female, FG 1).

However, one participant highlighted that although labels could have negative connotations for young people, the need for labels 'sort of depends', and that they may be valuable for some who 'need to know a problem', to help them understand what was happening. Despite this, this participant also felt it would be more useful for GPs to focus on the experience of symptoms, rather than diagnostic terms only:

I think maybe not defining them as, 'Right, you've got this', but... 'These are the symptoms round this' (Female, FG 1).

In regard to participants' perceptions on processes to conceptualise 'risk', structured risk assessment tools and processes were seen to be reductionist, as well as powerful-in the sense that they could potentially result in the young person receiving a rapid diagnosis or label, without accounting for the nuance in their lived experiences:

I think it's kind of terrifying how you can go in there, do the risk assessment... they're just going to take those answers from this one day and use that to sort of give you a mental health condition... you could have had a really bad day and say, 'I'm terrible' and from that... you could have depression, and that might not be the full scope of maybe what you're dealing with... like the one assessment, probably, I think is a little bit scary and daunting and maybe not enough. (Female, FG 2).

Participants also raised concerns with the approach of the medical system more broadly; the perceived wide use of labels and diagnoses which categorised young people as either well or 'sick'. This binary approach was perceived to impact access to healthcare, with participants concerned about being classified as 'not sick enough' to receive treatment. This extended to the process of 'risk assessments', which were seen as 'invalidating' for those who required support and treatment, but who may not be conceptualised as being 'at-risk':

It's (risk assessment) quite invalidating for those that want some help, but it's like, 'Oh, but if you're not at risk then you're not really...', you know. There's that kind of fear (of) being invalidated when you seek help, when you're 'not sick enough'. (Female, FG 2).

Participants highlighted how they could be experiencing symptoms of mental ill-health without necessarily needing a diagnosis, but still require support:

I think you can be really anxious, or you can be not having a good time without being depressed or without... officially having anxiety. You can just be going through a really rough patch where you (aren't) at risk, but you still need help. (Female, FG 2).

In contrast to this reductionist approach, participants wanted to be seen as a whole person by their GP, with all of their lived experience taken into account. They highlighted how 'learning the background' of someone and getting to know 'who they are' could help improve the accuracy of the assessment process, and help GPs to make more effective treatment recommendations:

Something small might happen... you have a fallout with your parents and then, you know, you want to be able to talk about that, because all that contributes to the overall risk assessment... So, they can then really understand, and then what they tell you as well, I think, would be more accurate. (Female, FG 1).

The GP going beyond a label or diagnosis, and instead, listening to participants' concerns, preferences and supporting them as an individual was perceived to be beneficial:

I think not being so trigger happy to give someone a diagnosis, but just listen to them, validate them and give them the supports they need in the meantime to process whatever they're going through. (Female, FG 2).

Participants also spoke of the importance of personalised care-they wanted the diversity of their symptoms 
and experiences acknowledged by their GP, both within themselves and as distinct from other young people. One participant described how having 'one fix for all of us' was 'not on', and others emphasised the variation across young people as a group, and how treatment may be hindered by overlooking their individuality:

Not everyone's, say, depression is the same. There's multiple different ones. So, it can sometimes be like put under the same label but what they're doing isn't helping at all. (Male, FG 1).

Related to this, participants wanted their GP to also focus on their strengths and protective factors, as well as their problems:

They need to know what makes you feel good as well... A lot of the time they can just focus on the negatives, so the positives need to be included because that's how you're going to end up better. (Female, FG 1).

Taken together, participants raised concerns that assessments of mental health, suicidal behaviour and self-harm could result in a young person receiving an unwanted label from the GP that ignored the uniqueness and complexity of their individual experiences and needs.

\section{The importance of GPs' attitudes}

Participants emphasised the importance of GPs' attitudes and the patient-doctor relationship when consulting about mental health and suicidal behaviour/self-harm, where an indifferent or impersonal attitude was seen as a barrier to honesty and disclosure. This attitude could be conveyed in a variety of interactions with the young person. Some participants reported experiencing a sense that GPs were only asking about their mental health because 'they're told that they need to', rather than out of genuine interest and concern. Similarly, when mental health or risk-related assessments were conducted in a 'tick-box', formulaic manner, this also hindered disclosure:

Even like the format in which questions are asked. If you feel like someone is just trying to tick boxes and just reading off a list and going, 'Okay, well how are you feeling today? Okay, well, have you felt sad in the past?', dah, dah, dah. It does not feel very personal or why would you want to tell somebody all these personal things about you if all they're trying to do is tick boxes. (Female, FG 2).

GPs' displaying attentive body language including eye contact and posture, and demonstrating active listening, were also important to young people when communicating about suicidal behaviour and/or self-harm:

Being a good listener is one of the vital things... and the way they sit as well. The way they sit or look at you, their gesture is very important. You don't want to be ignored at that moment when you're telling your story. (Female, FG 1).
You'd want your GP to kind of like face you and really look at you and be sincere so that you know that you're being addressed, and you know that you can say something. (Female, FG 2).

The initial reaction of GPs to the disclosure of suicidal behaviour, self-harm or mental health concerns was seen as crucial-not only to the likelihood of future disclosures, but also to young people's subsequent mental wellbeing. Participants described how perceived judgement from GPs could influence their openness and honesty:

When you talk about self-harm... when you (the GP) sound accusatory or angry or like you don't understand, people won't open up if they feel like they're going to be judged... you have to be calm and engaged but not like, aggressive. (Female, FG 2).

They also discussed how opening up to a GP requires vulnerability and trust, and outlined how negative responses from GPs could reinforce mental health difficulties, and possibly even exacerbate self-harming behaviours:

If you share that, you're sharing that because you trust them and you want to have a better response rather than, 'Oh, you shouldn't have done that. What's wrong with you?', you know what I mean? That can be a lot of the time what makes them do it (self-harm). (Female, FG 1).

Furthermore, having their concerns dismissed or minimised by the GP was problematic:

Sometimes the GP might say, for example... 'It happens to everybody, it's okay... you'll get over it'. You don't want to hear that, in a sense... it's actually kind of saying that it's nothing that you're going through... everybody goes through it, it's fine. It's not even an issue. (Female, FG 1).

Primarily, participants wanted their GPs to 'be friendly'. This kind of attitude was seen to encourage openness about their mental health concerns, suicidal behaviour, or self-harm:

I think just having a friendly person to communicate to... If you feel quite friendly, then you'll be able to be more honest. (Male, FG 1).

Participants observed that the attitudes of GPs could be influenced by their knowledge and skills around engaging and communicating with young people. They noted that this should be a focus of improvement for GPs when asking about suicidal behaviour or self-harm, and conducting risk assessments:

Just making... kind of offhand comments and just inappropriate... a lot of doctors have done it to me. I think that they've just got to learn to behave appropriately when asking (about) these things. (Female, FG 2). 
Finally, participants reflected on how time-limited consultations may affect GPs' attitudes and demeanour. Time constraints were felt to impact GPs' ability to adequately identify problems and to see the 'whole picture', were perceived to hinder the development of a genuine connection with the young person, and prevented GPs from viewing the young person as more than just a 'number':

Even just being treated like a number, like in and out. In and out. We just want you in and out. It's not about understanding or really knowing what's going on and how we can help. With so many mental health conditions, they fly under the radar. you've kind of got to dig deeper into that, and not just kick someone out of the appointment just to keep getting patients in. (Female, FG 2).

On the whole, participants expressed the view that young people would be more willing to talk to their GP about suicidal behaviour and self-harm if the GP had a friendly, non-judgemental attitude and showed genuine interest and concern.

\section{The provision of practical support}

Participants perceived crisis management as an essential skill for GPs, and discussed how the provision of immediate support and resources from GPs would be valuable to them:

Making sure the GPs know what to do in a like crisis... the GP can then go, 'Oh, young person, here's what you do if you're in a crisis', so that the young people are then aware as well... so that the GP has, like, handouts they can give. Like 'Call these numbers' or 'Go here'. (Male, FG 2).

However, they also expressed wanting to feel genuine interest and concern again from their GP when being provided with tangible support and resources, such as helplines and apps. This translated to more than GPs just giving the resources to the young person; rather, they wanted GPs to take the additional step of showing them how to access the resource, or testing them out together:

It just sort of feels like (a) protocol (providing a helpline)... it doesn't actually seem like they're just generally—that (they've) got (your) best interest at heart... If you do, take it through and show (the young person)-you know, then (they'll think), 'Oh, so this actually will help me’. (Female, FG 1).

Participants expressed that this 'rehearsal' of resources with GPs would make them more likely to use the resource when needed, by enhancing familiarity and comfort with accessing it. The 'acting out' of using a resource, such as calling a helpline, or practicing a safety plan, would 'resonate with you more' and may become 'embedded in you':

(Female): It would be better if they physically took you through (apps)... maybe if they physically put it on your phone. And show you how to go through it and then if there is a call line, maybe call them while you're with them and just so you can have that, like, experience. (Male): So it's not such a big jump for when you go from talking about it to, 'Oh well actually I need to call them'. (FG 1).

A few participants also highlighted how follow-up from GPs was an important part of receiving support for suicidality and/or self-harm. This basic process of checking how the young person was going and whether they were accessing the resources provided could also extend to an opportunity for further assistance if required:

I think maybe a certain degree of follow-up would be good, whether it's a phone call from them or the reception desk or someone, just to see how you are, how you're going, if you've followed up on the resources or not. (Female, FG 2).

Overall, participants felt that GPs providing them with practical resources, showing them how to access supports available, and active follow-up would be beneficial.

\section{DISCUSSION}

This study is the first to examine young people's perspectives on and experiences of the identification, assessment and care of suicidal behaviour and self-harm by GPs. We found a number of key considerations that are relevant to GPs' practices when working with young people who present with suicidal behaviour and/or self-harm, as well as mental health concerns more broadly.

\section{Key findings \\ Identification}

It was important to young people that their GPs initiate the conversation about mental health, suicide and self-harm. Such direct enquiry may alleviate some of the barriers to disclosure of suicidal thoughts, depressive symptoms ${ }^{43} 61$ or mental health problems more generally, ${ }^{62}$ and provide a valuable opportunity for intervention. However, previous research has identified that often GPs feel they lack the confidence and skills to enquire about and discuss suicidality and self-harm with young people, or that there may be negative outcomes associated with asking about these issues. ${ }^{4563}$ Clearly, this is an obstacle to providing the type of care that young people want, and GPs have outlined that they would welcome training in this area. ${ }^{45} 63$ Young people also expressed concerns regarding the privacy and confidentiality of their medical information relating to mental health and suicidal behaviour/self-harm. Protection of privacy has consistently been shown to be a major priority for young people in health services, particularly for sensitive issues. ${ }^{373964}$ As such, GPs should ensure that young people are aware of how their information will be collected, stored and used, and doing so is likely to result in improved disclosure of suicidal behaviours and/or self-harm. 


\section{Assessment}

In the context of risk assessments for suicidal behaviour and/or self-harm, young people expressed dislike towards the label of 'risk' and the term 'risk assessment' and perceived these to be potentially stigmatising and problematic. Stigma is by no means unique to young people, however, this population may be especially vulnerable to labels that could increase stigma, as they are experiencing a developmental period where identity formation and consolidation are paramount. ${ }^{65-67}$ Past research has shown that young people do find some of the language and terms used in mental health services to be pathologising, ${ }^{68}$ and our study suggests this extends to language related to suicidality or self-harm. While professionals commonly use the terms 'at-risk' and 'risk assessment', our findings support calls for a move away from clinicianfocused, to patient-focused language. ${ }^{69}$ The term 'coping assessment' has already been proposed as a replacement to 'risk assessment', 69 although participants in our study disliked the term 'assessment', and suggested the inclusion of language relating to 'well-being'.

Similarly, young people in our study disliked assessment approaches that were inflexible or binary. These were perceived as being overly simplistic, failing to capture nuance in young people's mental states and could negatively impact access to healthcare due to the labels or classification methods used. Instead, young people wanted to be seen by GPs in a holistic and individualised manner, with their strengths and the diversity of their lived experience acknowledged. This reinforces recommendations that traditional risk assessment methods that categorise patients into 'risk-level' groups should not be used to determine treatment outcomes, as they can miss key opportunities for intervention. ${ }^{52570}$ Further, these can feel impersonal to young people with their 'tick-box' or checklist-style approaches. Rather, our findings endorse the need for comprehensive psychosocialbased assessments that prioritise collaboration and the therapeutic alliance, are holistic, acknowledge that risk is dynamic over time, and are needs-driven-where individual circumstances are taken into account to determine appropriate management. ${ }^{52324}$ While psychosocial-based methods of assessment are recommended as best practice, no previous research has explored young people's preferences on the practices of risk conceptualisation. Individualised, needs-based approaches are also emphasised as key components of youth-friendly services, ${ }^{68}$ and our results reiterate that these are important features for young people when undergoing assessments for suicidal behaviour or self-harm.

\section{Care}

A key feature of the consultation should be a collaborative dialogue, which encompasses the provision of adequate and detailed information across all aspects of a young person's care, including treatment options and confidentiality. This dialogue should also facilitate empowerment and create opportunities for young people to be involved in treatment decisions. These preferences reflect young people's emerging developmental capacity for decision making and their growing needs for autonomy, agency and control. ${ }^{44656671}$ They are also consistent with young people's priorities in other types of health services, ${ }^{72} 73$ and with the principles of patient-centred care, shared decision making and patient engagement. ${ }^{74-77}$ In the context of suicidal behaviour and/or self-harm, these preferences should be acknowledged and supported as far as possible by GPs.

Young people may be particularly sensitive to power disparities and condescension, ${ }^{78}$ and as such, a genuine connection between the young person and GP, and GPs having a friendly, non-judgemental attitude are critical. Poor attitudes and body language and impersonal, overmedicalised approaches were seen as impediments to the development of a therapeutic alliance and the disclosure of suicidal behaviour/self-harm. Young people reported that negative reactions from GPs to a disclosure could result in escalation or exacerbation of their symptoms, and suggested that GPs might benefit from training and education in communication skills-again, a suggestion echoed by GPs themselves. ${ }^{45} 63$

While GPs have indicated previously that they try to prioritise listening and sensitive discussion, time constraints are a significant barrier. ${ }^{45}$ Young people indeed reported that time limitations in a busy clinical practice negatively influenced GPs' attitudes and ability to accurately conceptualise the young person's problems, suggesting that young people are not oblivious to the demands of GPs' roles. Despite time limitations, it remains essential that young people experience a positive therapeutic interaction during their engagement with services. Our findings underline the importance of medical professionals' interpersonal skills and support the need for compassionate approaches to suicide prevention. ${ }^{6979}$ Key features of good clinical and youthfriendly care, such as being non-judgemental, genuine, respectful, empathetic, and listening ${ }^{64}$ may help to alleviate suicidal distress by promoting a sense of connection and being cared for, and inspiring hope. ${ }^{81-83}$ Such positive interactions may also help to address some of the barriers to disclosure and identification of suicidal behaviour and/or self-harm, by laying the foundation for open and honest communication to occur. ${ }^{81}$

Young people expected GPs to be skilled and knowledgeable in providing practical resources and support for presentations of suicidal behaviour and self-harm, including crisis support. Assistance from the GP with accessing crisis resources or using a safety plan was viewed as highly beneficial, and GPs taking the time to demonstrate resources to the young person was seen to be another expression of care and connection that may assist the therapeutic relationship. Previous research has shown that while GPs often signpost resources and services, they are concerned that young people may lack the confidence or maturity to access these effectively. ${ }^{63}$ Additionally, young people may have had little previous 
experience of how the healthcare system is structured, ${ }^{84}$ and therefore might require more 'scaffolding' than adults. ${ }^{85}$ Rehearsal is an important part of learning, and frequently mental health service providers engage in behavioural rehearsal activities as part of suicide-related training programmes. ${ }^{86} 87$ Our findings then suggest that rehearsal could be extended to primary health practice when helping young people access mental health or suicide prevention-related resources. This might include calling helplines or using their safety plan, alongside the GP acting as a supportive guide.

Lastly, young people emphasised the importance of follow-up after a presentation involving risk of suicidal behaviour or self-harm. While follow-up is a recommended strategy for the management of depression and suicidality in primary care,${ }^{81889}$ rates of follow-up by GPs after diagnosing a young person with a psychological problem have been shown to require improvement. ${ }^{90}$ Active follow-up by GPs can provide an opportunity for further assistance, strengthen the therapeutic relationship and potentially mitigate isolation, hopelessness and increased vulnerability that can occur with disengagement. ${ }^{81}$

\section{Implications for practice}

Primary care services and GPs should deliver care for suicidality and self-harm in a way that is sensitive to young people's identified needs and preferences, and tailored to their developmental stage. ${ }^{44-94}$ Indeed, it has been argued that not doing so could adversely impact young people's future engagement with healthcare, satisfaction, and their eventual health and well-being-related outcomes. ${ }^{91} 94$

The development of resources, including tools to facilitate better risk assessments, could be potentially beneficial. Psychosocial assessment and interviewing formats would appear to be much more suited to populations of young people who might present with suicidal behaviour and/or self-harm. These may include instruments such as the HEEADSSS assessment, which uses an exploratory interviewing approach to collect information about key domains in a young person's life (ie, home, education/ employment, eating/exercise, activities/peer relationships, drug use, sexuality, suicide/depression, and safety), including risk factors or difficulties the young person might be experiencing, as well as their strengths and protective factors. ${ }^{95} 96$

Resources that assist young people to disclose mental health concerns to GPs may also be helpful. Electronic tools that use self-administered, psychosocial-based questionnaire formats to screen for risk and protective factors around youth mental health problems-such as the Check Up GP tool and the myAssessment app-have been shown to increase problem disclosure and improve perceptions of patient-centred care and time efficiency in consultations with young people. ${ }^{97} 98$ In the context of time-limited appointments, such tools could be useful and effective by allowing GPs to have a comprehensive understanding of a young person's problems, without adding to time burdens, and could serve as a basis (not replacement) for an open and collaborative discussion between young people and GPs.

Clinical decision support system tools can also assist GPs with the identification and management of suicide risk in young people and improve rates of follow-up. ${ }^{99} 100$ Such tools aim to enhance clinical decision making by guiding practitioners through the process of clinical assessment, consolidating patient information and providing related prompts and recommendations for follow-up.

Further, our findings reflect an urgent need for training for GPs around working with young patients with suicidal behaviours and/or self-harm, particularly in regards to communicating with young people, which has been reported previously. ${ }^{101}$ Training and resources should focus on GPs' therapeutic and communication styles, engagement, shared decision making, and comprehensive psychosocial approaches to assessing risk and protective factors for suicide and self-harm. Simple changes to GPs' communication with young people, such as adopting a friendly, approachable and non-judgemental demeanour, are not costly, nor do they add to time burdens. Even for practices that are short of resources, focusing on these interpersonal skills may bring significant benefits for suicide prevention with young people.

\section{Strengths and limitations}

The study was conducted with a relatively small sample of participants in one geographical region using convenience sampling methods. As participants self-selected to take part, there is a likelihood of selection bias in the sample. Thus, the findings may not be fully generalisable to all young people. However, this is not uncommon for this type of exploratory study, and we are satisfied that the sample offers new insights and understandings. ${ }^{57}$ It is also noted that while we sought to recruit young people with experience of discussing suicidality/self-harm with their GP, and it was evident from the interviews that participants had histories of suicidal behaviour/self-harm, there was no specific inclusion criteria for this. Similarly, the study included a small number of young people who had not undergone a risk assessment with a GP. While a limitation, it is important to note that qualitative paradigms are not necessarily concerned with achieving 'representativeness' of variables, ${ }^{102}$ and thus sample heterogeneity in terms of differing histories of suicidality/self-harm or risk assessments were not of particular significance. Instead, the focus was on exploring the phenomena of interestyoung people's broader opinions on, and experiences of, the identification, assessment and care practices conducted by GPs. Even being asked about suicidality/ self-harm or undergoing a risk assessment in the absence of risk can provide insight into young people's preferences for these processes, and similarly, not receiving a risk assessment can highlight the barriers to this occurring. Thus, we consider that it was important to include this diversity, although future studies could use stricter inclusion criteria. 
Finally, the study is novel in its focus; to the best of our knowledge it is the first to examine young people's views and experiences regarding the identification, assessment and care of suicidal behaviour and self-harm in the primary care setting. Several findings share similarities with those seen in the broader literature on young people's experiences of help-seeking, disclosure, and service use needs for mental health treatment. ${ }^{3739-41}$ This suggests that these are consistent concerns and priorities for young people, as well as critical components of good clinical practice that are relevant to suicide and self-harm presentations.

\section{CONCLUSION}

GPs play an essential role in youth suicide prevention by engaging in the detection, assessment and care of suicidal behaviour and self-harm, however, to date, significant barriers exist that may limit these processes. Our study identified a number of factors that affect young people's willingness to disclose risk of suicide and self-harm to GPs, as well as some key facilitators to disclosure, including being adequately informed, the presence of clear and non-judgemental communication, and having a positive therapeutic relationship with the GP. The use of holistic risk assessments, and the provision of collaborative, individualised care with tangible support and resources from GPs appear preferable to young people. Taken together, these findings can help inform what constitutes youthfriendly best practice for suicidal behaviour and self-harm in primary care.

\section{Author affiliations}

${ }^{1}$ Orygen, Parkville, Victoria, Australia

${ }^{2}$ Centre for Youth Mental Health, The University of Melbourne, Parkville, Victoria, Australia

${ }^{3}$ Telethon Kids Institute, The University of Western Australia, Perth Children's Hospital, Nedlands, Western Australia, Australia

${ }^{4}$ School of Psychology, Institute for Mental Health, University of Birmingham, Birmingham, UK

${ }^{5}$ School of Psychology, Faculty of Science, The University of Auckland, Auckland, New Zealand

${ }^{6}$ Gold Coast University Hospital, Southport, Queensland, Australia

${ }^{7}$ Department of Psychological Medicine, Faculty of Medical and Health Sciences, The University of Auckland, Auckland, New Zealand

Acknowledgements We sincerely thank all of the young people who took part in the study and shared their experiences with us.

Contributors Contributions are described as per the CRediT taxonomy (https:// casrai.org/credit). IBW conducted formal analysis, project administration, validation, visualisation and writing (original draft preparation). YP conducted investigation and project administration. KK conducted validation. SJB conducted investigation. $A B$ conducted formal analysis. MM conducted conceptualisation and methodology. ML conducted project administration. KLG conducted validation. AL conducted project administration. TYL conducted conceptualisation and was a youth advisor on the project. SH conducted conceptualisation and methodology. JR conducted conceptualisation, funding acquisition, investigation, methodology, project administration and supervision. All authors conducted writing (reviewing and editing).

Funding This work was supported by the WA Primary Health Alliance (WAPHA) as part of the National Suicide Prevention Trial, through the Australian Government PHN Program. JR and AL are funded by National Health and Medical Research
Council Career Development Fellowships (JR: 1142348; AL: 1148793). YP is funded by The Giorgetta Charity Fund.

Disclaimer None of the funding bodies had any role in the design of the study, in the collection, analyses, or interpretation of the data, in the writing of the manuscript, or in the decision to publish the results.

Competing interests IBW, KK, SJB, AB, ML, TYL and JR report grants from the WA Primary Health Alliance (WAPHA) to enable the conduct of this study. SH reports that she is the joint coordinating editor of the Cochrane Common Mental Disorders Group and manages the Children and Young People Satellite. She has funding from the Royal Society, the Faculty of Medical and Health Sciences at the University of Auckland, and Cochrane to pursue this work, including systematic reviews in the area of children and young people's mental health. She is funded by the Auckland Medical Research Foundation to develop and test an app that delivers goal setting for young people with mental health and related difficulties, such as self-harm. She is a CureKids Research Fellow, working on developing digital tools to support parents to support children with mental health and related difficulties. YP, MM, KLG and $\mathrm{AL}$ report nothing to disclose.

Patient consent for publication Not required.

Ethics approval The study was granted ethical approval by The University of Melbourne Human Research Ethics Committee (HREC ID: 1748913). Written informed consent was obtained from all participants, who were able to withdraw their consent at any time.

Provenance and peer review Not commissioned; externally peer reviewed.

Data availability statement Anonymised focus group transcripts are available at Orygen, Suicide Prevention. These may be accessed on reasonable request by contacting author IBW at india.bellairs-walsh@orygen.org.au.

Supplemental material This content has been supplied by the author(s). It has not been vetted by BMJ Publishing Group Limited (BMJ) and may not have been peer-reviewed. Any opinions or recommendations discussed are solely those of the author(s) and are not endorsed by BMJ. BMJ disclaims all liability and responsibility arising from any reliance placed on the content. Where the content includes any translated material, BMJ does not warrant the accuracy and reliability of the translations (including but not limited to local regulations, clinical guidelines, terminology, drug names and drug dosages), and is not responsible for any error and/or omissions arising from translation and adaptation or otherwise.

Open access This is an open access article distributed in accordance with the Creative Commons Attribution Non Commercial (CC BY-NC 4.0) license, which permits others to distribute, remix, adapt, build upon this work non-commercially, and license their derivative works on different terms, provided the original work is properly cited, appropriate credit is given, any changes made indicated, and the use is non-commercial. See: http://creativecommons.org/licenses/by-nc/4.0/.

Author information The authors who conducted data collection, analysis, and interpretation are all researchers with psychology-related backgrounds and qualifications (such as Bachelors, Honours, Masters, and PhD degrees). They have a diverse range of professional experience working with young people around the topic of suicide and self-harm, and in consumer-orientated service use. The authors subscribe to youth-empowerment perspectives and are committed to providing young people with a voice that captures the quality and diversity of their personal experiences, to ensure their needs are identified and supported by services they use.

\section{ORCID iD}

India Bellairs-Walsh http://orcid.org/0000-0001-9480-7881

\section{REFERENCES}

1 Australian Bureau of Statistics. Australian Bureau of Statistics. Causes of death, Australia, 2018. Canberra, Australia, 2019

2 O'Connor RC, Nock MK. The psychology of suicidal behaviour. Lancet Psychiatry 2014;1:73-85.

3 Lawrence D, Johnson S, Hafekost J, et al. The mental health of children and adolescents: report on the second Australian child and adolescent survey of mental health and wellbeing. Canberra: Department of Health, 2015.

4 Kapur N, Cooper J, O'Connor RC, et al. Non-suicidal self-injury v. attempted suicide: new diagnosis or false dichotomy? $\mathrm{Br} \mathrm{J}$ Psychiatry 2013;202:326-8.

5 National Collaborating Centre for Mental Health. Self-harm: longerterm management. Leicester, UK: The British Psychological Society \& The Royal College of Psychiatrists, 2012. 
6 Johnston AK, Pirkis JE, Burgess PM. Suicidal thoughts and behaviours among Australian adults: findings from the 2007 national survey of mental health and wellbeing. Aust N Z J Psychiatry 2009;43:635-43.

7 De Leo D, Heller TS. Who are the kids who self-harm? An Australian self-report school survey. Med J Aust 2004;181:140-4.

8 Moran P, Coffey C, Romaniuk $\mathrm{H}$, et al. The natural history of selfharm from adolescence to young adulthood: a population-based cohort study. Lancet 2012;379:236-43.

9 Hawton K, Fagg J. Suicide, and other causes of death, following attempted suicide. Br J Psychiatry 1988;152:359-66.

10 Ribeiro JD, Franklin JC, Fox KR, et al. Self-injurious thoughts and behaviors as risk factors for future suicide ideation, attempts, and death: a meta-analysis of longitudinal studies. Psychol Med 2016;46:225-36.

11 Hawton K, Bergen H, Kapur N, et al. Repetition of self-harm and suicide following self-harm in children and adolescents: findings from the multicentre study of self-harm in England. J Child Psychol Psychiatry 2012;53:1212-9.

12 Knorr AC, Tull MT, Anestis MD, et al. The interactive effect of major depression and nonsuicidal self-injury on current suicide risk and lifetime suicide attempts. Arch Suicide Res 2016;20:539-52.

13 Carr MJ, Ashcroft DM, Kontopantelis E, et al. Premature death among primary care patients with a history of self-harm. Ann Fam Med 2017;15:246-54.

14 Carter G, Reith DM, Whyte IM, et al. Repeated self-poisoning: increasing severity of self-harm as a predictor of subsequent suicide. Br J Psychiatry 2005;186:253-7.

15 Horowitz LM, Bridge JA, Pao M, Boudreaux ED, et al. Screening youth for suicide risk in medical settings: time to ask questions. Am J Prev Med 2014;47:S170-5.

16 Australian Institute of Health and Welfare. Mental health services in Australia. Canberra, Australia: Australian Institute of Health and Welfare, 2019.

17 Productivity Commission. Mental health, draft report. Canberra, Australia: Commonwealth of Australia, 2019.

18 Luoma JB, Martin CE, Pearson JL. Contact with mental health and primary care providers before suicide: a review of the evidence. Am J Psychiatry 2002:159:909-16.

19 Rhodes AE, Khan S, Boyle MH, et al. Sex differences in suicides among children and youth: the potential impact of help-seeking behaviour. Can J Psychiatry 2013;58:274-82.

20 Sayal K, Yates N, Spears M, et al. Service use in adolescents at risk of depression and self-harm: prospective longitudinal study. Soc Psychiatry Psychiatr Epidemiol 2014;49:1231-40.

21 Michail M, Mughal F, Robinson J. Suicide prevention in young people: optimising primary care. Br J Gen Pract 2020;70:104-5.

22 General Practice Mental Health Standards Collaboration. Mental health training standards 2020-22: a guide for general practitioners. East Melbourne, VIC: Royal Australian College of General Practitioners, 2019

23 Hawgood J, De Leo D. Suicide prediction - a shift in paradigm is needed. Crisis 2016;37:251-5.

24 Hawgood J, De Leo D. Reconceptualising suicide risk assessment: a person-centred approach to needs-based exploration of current suicidality. InPsych: The Bulletin of the Australian Psychological Society Ltd 2016;38:10.

25 Mulder R, Newton-Howes G, Coid JW. The futility of risk prediction in psychiatry. Br J Psychiatry 2016;209:271-2.

26 Large M, Kaneson M, Myles N, et al. Meta-analysis of longitudinal cohort studies of suicide risk assessment among psychiatric patients: heterogeneity in results and lack of improvement over time. PLoS One 2016;11:e0156322.

27 Mulder R. Problems with suicide risk assessment. London, UK: Sage Publications, 2011: 45. 605-7.

28 National Collaborating Centre for Mental Health. Self-harm: the short-term physical and psychological management and secondary prevention of self-harm in primary and secondary care. Leicester, UK: The British Psychological Society \& The Royal College of Psychiatrists, 2004

29 General Practice Mental Health Standards Collaboration. Suicide prevention and first aid: a resource for GPs. East Melbourne, VIC: Royal Australian College of General Practitioners, 2016.

30 Gordon M, Melvin G. Risk assessment and initial management of suicidal adolescents. Aust Fam Physician 2014;43:367-72.

31 Royal Australian College of General Practitioners. Guidelines for preventive activities in general practice. 9 ed. East Melbourne, VIC: Royal Australian College of General Practitioners, 2018.

32 Michail M, Mughal F. Suicide in children and young people: tips for GPs. Royal College of General Practitioners, 2018. Available:
https://www.rcgp.org.uk/-/media/Files/CIRC/Clinical-News/Feb2018/RCGP-suicide-top-tips-feb-2018.ashx?la=en

33 Sinclair L, Leach R. Exploring thoughts of suicide. BMJ 2017;356:j1128.

34 World Health Organization. Preventing suicide: a resource for primary health care workers. Geneva: World Health Organization, 2000.

35 Tait L. To disclose or not to disclose psychological problems to GPs. Br J Gen Pract 2009;59:638-9.

36 Biddle L, Donovan JL, Gunnell D, et al. Young adults' perceptions of GPs as a help source for mental distress: a qualitative study. $\mathrm{Br} \mathrm{J}$ Gen Pract 2006:56:924-31.

37 Jacobson L, Richardson G, Parry-Langdon N, et al. How do teenagers and primary healthcare providers view each other? An overview of key themes. Br J Gen Pract 2001;51:811-6.

38 Leahy D, Schaffalitzky E, Saunders J, et al. Role of the general practitioner in providing early intervention for youth mental health: a mixed methods investigation. Early Interv Psychiatry 2018:12:202-16.

39 Carlisle J, Shickle D, Cork M, et al. Concerns over confidentiality may deter adolescents from consulting their doctors. A qualitative exploration. J Med Ethics 2006:32:133-7.

40 Bailey D, Kemp L, Wright N, et al. Talk about self-harm (TASH): participatory action research with young people, GPs and practice nurses to explore how the experiences of young people who self-harm could be improved in GP surgeries. Fam Pract 2019:36:621-6.

41 Freake H, Barley V, Kent G. Adolescents' views of helping professionals: a review of the literature. J Adolesc 2007;30:639-53.

42 Joiner TE, Pfaff JJ, Acres JG. Characteristics of suicidal adolescents and young adults presenting to primary care with nonsuicidal (indeed non-psychological) complaints. Eur J Public Health 2002;12:177-9.

43 Wilson CJ, Deane FP, Marshall KL, et al. Adolescents' suicidal thinking and reluctance to consult general medical practitioners. $J$ Youth Adolesc 2010;39:343-56.

44 Tylee A, Haller DM, Graham T, et al. Youth-friendly primary-care services: how are we doing and what more needs to be done? Lancet 2007;369:1565-73.

45 Michail M, Tait L. Exploring general practitioners' views and experiences on suicide risk assessment and management of young people in primary care: a qualitative study in the UK. BMJ Open 2016;6:e009654-e54.

46 Larsson I, Staland-Nyman C, Svedberg P, et al. Children and young people's participation in developing interventions in health and wellbeing: a scoping review. BMC Health Serv Res 2018;18:507.

47 Clarke S. A "child's rights perspective": the "right" of children and young people to participate in health care research. Issues Compr Pediatr Nurs 2015;38:161-80.

48 National Health and Medical Research Council, Consumers Health Forum of Australia. Statement on consumer and community involvement in health and medical research. Canberra, Australia: National Health and Medical Research Council, 2016.

49 Braun V, Clarke V, et al. Thematic analysis. In: Cooper H, Camic PM, Long DL, et al, eds. APA handbook of research methods in psychology: quantitative, qualitative, neuropsychological, and biological. 2: Research design. Washington, DC: American Psychological Association, 2012: 57-71.

50 The Senate, Community Affairs References Committee. Accessibility and quality of mental health services in rural and remote Australia. Canberra, Australia. Commonwealth of Australia; 2018. https://www.aph.gov.au/Parliamentary Business/ Committees/Senate/Community_Affairs/MentalHealthServices/ Report

51 Tong A, Sainsbury P, Craig J. Consolidated criteria for reporting qualitative research (COREQ): a 32-item checklist for interviews and focus groups. Int J Qual Health Care 2007:19:349-57.

52 Roller MR, Lavrakas PJ. Applied qualitative research design: a total quality framework approach. 1 ed. New York, NY: Guilford Press, 2015: 398

53 Lundh L-G, Wångby-Lundh M, Paaske M, et al. Depressive symptoms and deliberate self-harm in a community sample of adolescents: a prospective study. Depress Res Treat 2011;2011:1-11.

54 Gemmill R, Williams AC, Cooke L, et al. Challenges and strategies for recruitment and retention of vulnerable research participants: promoting the benefits of participation. Appl Nurs Res 2012;25:101-7.

55 Thomas N, O'Kane C, O'Kane C. The ethics of participatory research with children. Children \& Society 1998;12:336-48. 
56 Guest G, Bunce A, Johnson L. How many interviews are enough? An experiment with data saturation and variability. Field Methods 2006;18:59-82.

57 Malterud K, Siersma VD, Guassora AD. Sample size in qualitative interview studies: guided by information power. Qual Health Res 2016;26:1753-60.

58 Braun V, Clarke V. Using thematic analysis in psychology. Qual Res Psychol 2006;3:77-101.

59 Creswell JW, Miller DL. Determining validity in qualitative inquiry. Theory Pract 2000;39:124-30.

60 Hill CE, Knox S, Thompson BJ, et al. Consensual qualitative research: an update. J Couns Psychol 2005;52:196-205.

61 Wilson CJ, Deane FP. Help-negation and suicidal ideation: the role of depression, anxiety and hopelessness. J Youth Adolesc 2010;39:291-305.

62 Rickwood DJ, Deane FP, Wilson CJ. When and how do young people seek professional help for mental health problems? Med J Aust 2007;187:S35.

63 Fox F, Stallard P, Cooney G. GPs role identifying young people who self-harm: a mixed methods study. Fam Pract 2015;32:415-19.

64 Gibson K, Cartwright C, Kerrisk K, et al. What young people want: a qualitative study of adolescents' priorities for engagement across psychological services. J Child Fam Stud 2016;25:1057-65.

65 Christie D, Viner R. Adolescent development. BMJ 2005;330:301-4

66 Arnett JJ. Emerging adulthood: a theory of development from the late teens through the twenties. Am Psychol 2000;55:469-80.

67 Moses T. Self-labeling and its effects among adolescents diagnosed with mental disorders. Soc Sci Med 2009;68:570-8.

68 Hawke LD, Mehra K, Settipani C, et al. What makes mental health and substance use services youth friendly? A scoping review of literature. BMC Health Serv Res 2019;19:257.

69 Stallman HM. Coping planning: a patient-centred and strengthsfocused approach to suicide prevention training. Australas Psychiatry 2018;26:141-4.

70 Carter G, Milner A, McGill K, et al. Predicting suicidal behaviours using clinical instruments: systematic review and meta-analysis of positive predictive values for risk scales. $\mathrm{Br} J$ Psychiatry 2017;210:387-95.

71 Lerner RM, Steinberg L. Handbook of adolescent psychology. 1: individual bases of adolescent development. Hoboken, NJ: John Wiley \& Sons, 2009.

72 Gibson K, Cartwright C. Agency in young clients' narratives of counseling: "it's whatever you want to make of it". J Couns Psychol 2013;60:340-52.

73 Gibson K, Cartwright C. Young people's experiences of mobile phone text counselling: balancing connection and control. Child Youth Serv Rev 2014;43:96-104.

74 Davis K, Schoenbaum SC, Audet A-M. A 2020 vision of patientcentered primary care. J Gen Intern Med 2005;20:953-7.

75 Joseph-Williams N, Elwyn G, Edwards A. Knowledge is not power for patients: a systematic review and thematic synthesis of patientreported barriers and facilitators to shared decision making. Patient Educ Couns 2014;94:291-309.

76 Orygen, The National Centre of Excellence in Youth Mental Health. Shared decision making. Parkville, VIC. Orygen, The National Centre of Excellence in Youth Mental Health; 2016. https://www. orygen.org.au/Training/Resources/General-resources/Clinicalpractice-points/Shared-decision-making/Shared-decision-making

77 Simmons M, Hetrick S, Jorm A, et al. Barriers and current opportunities for application. Australas Psychiatry 2010:18:394-7.

78 Hanna FJ, Hunt WP. Techniques for psychotherapy with defiant, aggressive adolescents. Psychother Theor Res Pract Train 1999;36:56-68.

79 Cole-King A, Green G, Gask L, et al. Suicide mitigation: a compassionate approach to suicide prevention. Adv Psychiatr Treat 2013;19:276-83.

80 Lees D, Procter N, Fassett D. Therapeutic engagement between consumers in suicidal crisis and mental health nurses. Int J Ment Health Nurs 2014;23:306-15.
81 Samaritans. Strengthening the frontline: investing in primary care for effective suicide prevention. London, UK: Centre for Mental Health, 2019.

82 Collins S, Cutcliffe JR. Addressing hopelessness in people with suicidal ideation: building upon the therapeutic relationship utilizing a cognitive behavioural approach. J Psychiatr Ment Health Nurs 2003;10:175-85.

83 Cooper J, Hunter C, Owen-Smith A, et al. "Well it's like someone at the other end cares about you." A qualitative study exploring the views of users and providers of care of contact-based interventions following self-harm. Gen Hosp Psychiatry 2011;33:166-76.

84 James AM. Principles of youth participation in mental health services. Med J Aust 2007;187:S57.

85 Roisman GI, Masten AS, Coatsworth JD, et al. Salient and emerging developmental tasks in the transition to adulthood. Child Dev 2004;75:123-33.

86 Beidas RS, Cross W, Dorsey S. Show me, don't tell me: behavioral rehearsal as a training and analogue fidelity tool. Cogn Behav Pract 2014;21:1-11.

87 Murray LK, Skavenski S, Bass J, et al. Implementing evidencebased mental health care in low-resource settings: a focus on safety planning procedures. J Cogn Psychother 2014;28:168-85.

88 Cheung $\mathrm{AH}$, Zuckerbrot RA, Jensen PS, et al. Guidelines for adolescent depression in primary care (GLAD-PC): II. Treatment and ongoing management. Pediatrics 2007;120:e1313-26.

89 King CA, Foster CE, Rogalski KM. Teen suicide risk: a practitioner guide to screening, assessment, and management. New York, NY: Guilford Press, 2013.

90 Hetlevik $\varnothing$, Bjørnå $\mathrm{CH}$, Lundring I-T, et al. GP follow-up after first diagnosing psychological problems among adolescents: a nationwide register-based study. Br J Gen Pract 2018;68:e794-802.

91 Farre A, Wood V, Rapley T, et al. Developmentally appropriate healthcare for young people: a scoping study. Arch Dis Child 2015:100:144-51.

92 D'Agostino NM, Penney A, Zebrack B. Providing developmentally appropriate psychosocial care to adolescent and young adult cancer survivors. Cancer 2011;117:2329-34.

93 Dovey-Pearce G, Rapley T, McDonagh JE. Delivering developmentally appropriate health care: roles for psychologists as members of the multi-disciplinary health care team. Clin Child Psychol Psychiatry 2020;25:579-93.

94 Dovey-Pearce G, Hurrell R, May C, et al. Young adults' (16-25 years) suggestions for providing developmentally appropriate diabetes services: a qualitative study. Health Soc Care Community 2005;13:409-19.

95 Klein DA, Goldenring JM, Adelman WP. HEEADSSS 3.0: the psychosocial interview for adolescents updated for a new century fueled by media. Contemp Pediatr 2014;January:16-28.

96 Goldenring JM, Rosen DS. Getting into adolescent heads: an essential update. Contemp Pediatr 2004;21:64-92.

97 Webb MJ, Wadley G, Sanci LA. Improving patient-centered care for young people in general practice with a codesigned screening APP mixed methods study. JMIR Mhealth Uhealth 2017;5:e118.

98 Bradford S, Rickwood D. Acceptability and utility of an electronic psychosocial assessment (myAssessment) to increase selfdisclosure in youth mental healthcare: a quasi-experimental study. BMC Psychiatry 2015;15:305.

99 Horrocks M, Michail M, Aubeeluck A, et al. An electronic clinical decision support system for the assessment and management of suicidality in primary care: protocol for a mixed-methods study. JMIR Res Protoc 2018;7:e11135.

100 Etter DJ, McCord A, Ouyang F, et al. Suicide screening in primary care: use of an electronic screener to assess suicidality and improve provider follow-up for adolescents. J Adolesc Health 2018;62:191-7.

101 Mughal F, Troya MI, Dikomitis L, et al. Role of the GP in the management of patients with self-harm behaviour: a systematic review. Br J Gen Pract 2020;70:e364-73.

102 Charmaz K. Constructing grounded theory: a practical guide through qualitative analysis. London, UK: Sage Publications, 2006. 